\title{
ASSESSMENT OF ULTIMATE DRIFT CAPACITY OF RC SHEAR WALLS BY KEY DESIGN PARAMETERS
}

\author{
Chanipa Netrattana ${ }^{1}$, Rafik Taleb ${ }^{1}$, Hidekazu Watanabe ${ }^{2}$, \\ Susumu Kono ${ }^{3}$, David Mukai ${ }^{4}$, Masanori Tani ${ }^{5}$ \\ and Masanobu Sakashita ${ }^{6}$
}

(Submitted March 2017; Reviewed May 2017; Accepted September 2017)

\begin{abstract}
The latest version of the Standard for Structural Calculation of Reinforced Concrete Structures, published by the Architectural Institute of Japan in 2010 [1], allows the design of shear walls with rectangular cross sections in addition to shear walls with boundary columns at the end regions (referred to here as "barbell shape"). In recent earthquakes, several reinforced concrete (RC) shear walls were damaged by flexural failures through concrete compression crushing accompanied with buckling of longitudinal reinforcement in the boundary areas. Damage levels have clearly been shown to be related to drift in structures; this is why drift limits are in place for structural design criteria. A crucial step in designing a structure to accommodate these drift limits is to model the ultimate drift capacity. Thus, in order to reduce damage from this failure mode, the ultimate drift capacity of RC shear walls needs to be estimated accurately. In this paper, a parametric study of the seismic behaviour of RC shear walls was conducted using a fibre-based model to investigate the influence of basic design parameters including concrete strength, volumetric ratio of transverse reinforcement in the confined area, axial load ratio and boundary column dimensions. This study focused on ultimate drift capacity for both shear walls with rectangular sections and shear walls with boundary columns. The fibre-based model was calibrated with experimental results of twenty eight tests on shear walls with confinement in the boundary regions. It was found that ultimate drift capacity is most sensitive to axial load ratio; increase of axial load deteriorated ultimate drift capacity dramatically. Two other secondary factors were: increased concrete strength slightly reduced ultimate drift capacity while increased shear reinforcement ratio and boundary column width improved ultimate drift capacity.
\end{abstract}

\section{INTRODUCTION}

Slender reinforced concrete walls are an important part of a building's lateral load resisting systems. The 1999 Standard for Structural Calculation of Reinforced Concrete Structures [2] mandated the use of structural walls with boundary columns. In 2010 , the standard was revised to allow structural walls with rectangular cross sections (that is, without boundary columns) for buildings higher than five stories. To avoid catastrophic failure, structural walls are normally designed to have high shear resistance relative to flexural resistance and consequently fail in a ductile flexural mode.

The 2010 Chile Earthquake caused severe damage to a large number of RC structural walls in mid-rise and high-rise buildings. The observed damage included crushing of concrete and buckling of vertical reinforcement. The concrete crushing was severe at the boundary regions and often propagated along the wall length. This type of damage is a result of flexural compression failure mode and/or flexural tension failure mode $[3,4]$. Flexural compression failure occurs when the compression strain of concrete in the boundary region exceeds the compression limit strain. After crushing of concrete occurs, the longitudinal reinforcement buckles. Another failure mode occurs when the longitudinal reinforcement is elongated in tension before reversal into compression that causes buckling. This buckling of vertical reinforcement is followed by crushing of the concrete and is referred to as flexural tension failure [4]. More flexural failure of shear walls were observed in the 2016
Kumamoto Earthquake event. While most RC structural walls only suffered minor crack damage, some walls had severe damage due to cracking of concrete and buckling of longitudinal reinforcement, particularly at the ends of the walls [5]. Figure 1 presents damage of structural walls in the 2010 Chile earthquake and the 2016 Kumamoto earthquake. According to these observations, flexural failure can be considered as one of the most common failure modes of RC structural walls. This study focuses only on the failure caused by crushing of concrete and fracture of longitudinal reinforcement, and thus assumes that the boundary area has properly detailed confinement to prevent longitudinal reinforcement from buckling.

Zhang and Wang [6] tested four rectangular RC shear walls to investigate the effects of axial load ratio and shear compression ratio on the seismic behaviour of the walls. Axial load ratio is the ratio of applied axial load to the compressive capacity of the gross concrete section, while shear compression ratio is the ratio of maximum shear to the compressive capacity of the gross concrete section. Two of four specimens had the same configuration and reinforcement detailing, but different axial load ratios, 0.24 and 0.35 . Test results showed that the wall subjected to the higher axial load ratio of 0.35 failed by global out-of-plane buckling, thus exhibiting low displacement ductility. The definition of displacement ductility used by Zhang and Wang is the ultimate displacement divided by yield displacement. Su and Wong [7] also conducted an experiment of three rectangular RC shear walls to study the effects of axial

\footnotetext{
1 Graduate Student, Tokyo Institute of Technology,YYokohama,netrattana.c.aa@m.titech.ac.jp taleb_rafik@yahoo.fr

2 Assistant Professor, Tokyo Institute of Technology,Yokohama,watanabe.h.as@m.titech.ac.jp

3 Professor, Tokyo Institute of Technology, Yokohama,kono.s.ae@m.titech.ac.jp

4 Associate Professor, University of Wyoming, Laramie, (Visiting Associate Professor, Tokyo Institute of Technology), dmukai@uwyo.edu

5 Associate Professor, Kyoto University, Kyoto, tani@archi.kyoto-u.ac.jp

${ }^{6}$ Research Fellow, Building Research Institute, Tsukuba, m-saka@kenken.go.jp
} 
load ratio and confinement on their seismic performance. The walls had two levels of volumetric transverse reinforcement ratio, $0.54 \%$ and $1.08 \%$, and two levels of axial load ratio, 0.25 and 0.5. Interestingly, the two specimens with different volumetric transverse reinforcement ratio had similar ductility. Typically, specimens with higher transverse reinforcement ratios are expected to be more ductile. One reason for the ductility not being affected by transverse reinforcement might be that if the transverse reinforcement is not spread along the height of the wall, the confinement might not be effective. It is expected that if the transverse reinforcement is properly detailed, it would improve drift capacity. It was also found that when axial load was increased, maximum rotation ductility decreased and the specimens exhibited global out-of-plane failure.

Kono et al. [9] tested two structural walls with barbell shape cross sections (walls with boundary columns) and two walls with rectangular cross sections. Each cross section type had two levels of transverse reinforcement. Their objective was to study effects of boundary columns and confinement on seismic performance of structural walls. Their experimental results confirmed that walls with higher transverse reinforcement ratios had larger ultimate drift in both rectangular and barbell shape cross sections. Although walls with boundary columns had lower transverse reinforcement ratios than rectangular walls, they exhibited more ductile behaviour with larger ultimate drifts.

In summary, previous research has shown that axial load ratio has a significant influence on flexural strength, ductility and failure mode of structural walls. Two findings pertinent to this work are that a high axial load ratio reduces lateral drift capacity and properly arranged transverse reinforcement increases lateral drift of structural walls.

This paper aims to clarify the effects of four important parameters on seismic behaviour of RC shear walls: 1) concrete

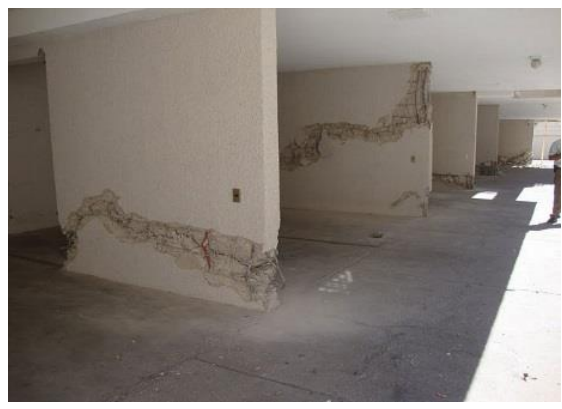

(a)

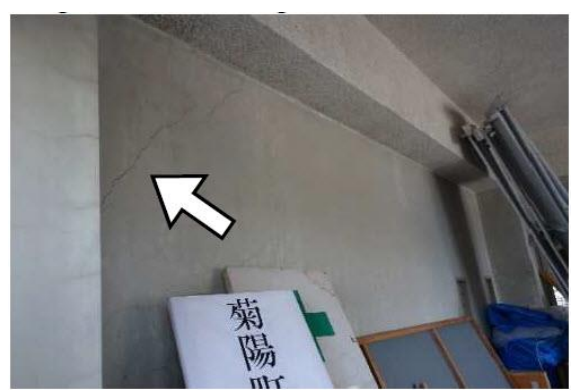

(c) strength, 2) volumetric transverse reinforcement ratio, 3) axial load ratio and 4) confined concrete area. Particular attention is given to ultimate drift capacity. While previous researchers have conducted experiments to study the effects of these parameters, the effect of these four parameters on drift angle and lateral load capacity remains unclear.

This study deals with reinforced concrete walls loading in the in-plane direction. The failure modes of $\mathrm{RC}$ walls loaded in the in-plane direction includes crushing of concrete in the compression zone, buckling and fracture of longitudinal reinforcement in the boundary column, shear failure of wall panels and boundary columns, shear sliding, and global buckling of boundary columns and wall panels. This paper provides a simulation of the ultimate drift capacity caused by crushing of concrete and fracture of longitudinal reinforcement assuming other failure modes are not taking place. In order to avoid analysis complication, the ultimate drift capacity from other failure modes will be studied in future work. The ultimate drift capacity caused by other failure modes need other procedures which are out of the scope of this paper.

\section{DESCRIPTION OF MODEL}

In this parametric study, compression failure of concrete and tensile fracture of longitudinal reinforcement was simulated excluding other failure modes such as buckling of longitudinal reinforcement, shear failure of wall panels and boundary columns, shear sliding, and global buckling of boundary columns and wall panels. Other failure modes are equally important but should be modelled separately to avoid complication. It is true that fibre models are unable to simulate localized behaviour, especially at the stress concentration point. However, the fibre model generally simulates the local behaviour (stress and strain) in an average sense.

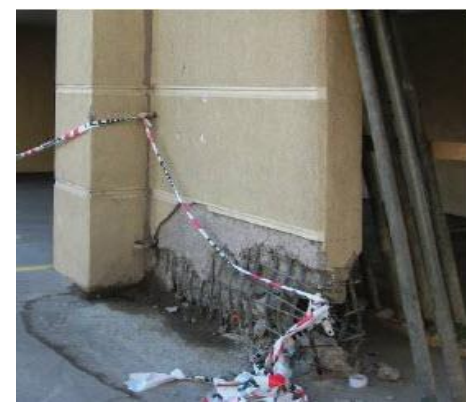

(b)

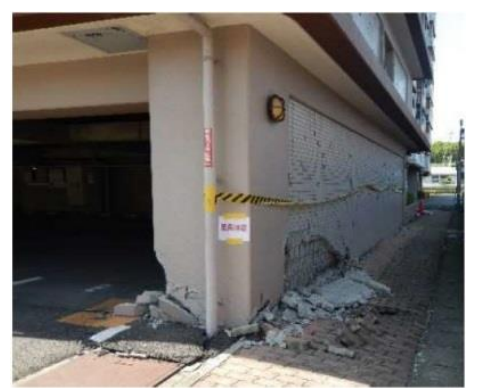

(d)

Figure 1: Damage of structural walls by the 2010 Chile earthquake (a-b) [8,4] and the 2016 Kumamoto earthquake (c-d) [5]; (a) Crushing of concrete along wall length; (b) Flexural hinge on walls; (c) Minor cracks in shear wall; and (d) Spalling of concrete in shear wall. 


\section{Geometric Modelling}

Reinforced concrete walls are modelled with a fibre-based model. In the fibre-based model, the cross section of concrete is divided into layers stacked along the loading direction with thickness of $7 \mathrm{~mm}$ to $10 \mathrm{~mm}$. Each steel reinforcing bar is modelled as single element. Out-of-plane buckling is not considered in the analysis. Effects of confinement are taken into account by modelling the concrete inside the transverse reinforcement with a confined concrete model. The remaining concrete is modelled as plain concrete. In Figure 2, the blue elements are confined concrete while the yellow elements are plain concrete. The model assumes perfect bonding between concrete and longitudinal reinforcement. Figure 2 presents the elements in the fibre-based model of tested walls, which are NC40, NC80, BC40 and BC80 [9]. In the fibre-based model, the strain in each layer is computed under the assumption that plane sections remain plane (i.e. strain is linear with distance from the neutral axis).

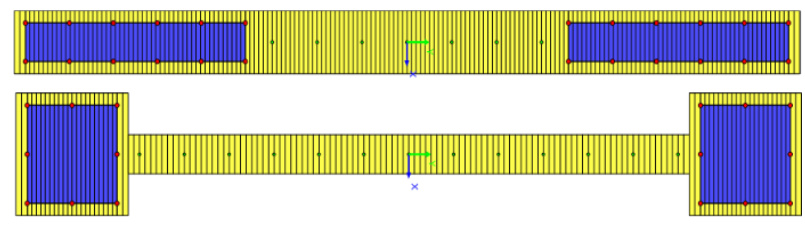

Figure 2: Elements in the fibre-based model of NC40\&NC80 (rectangular section) and BC40\&BC80 (barbell shape).

\section{Material Modelling}

The stress-strain relationships under cyclic loading for reinforcement and concrete are necessary to calculate stress. In reinforced concrete structural members, the confinement provided by transverse reinforcement improves the compressive strength and ultimate strain of concrete [10]. The Modified Kent and Park model provides a monotonic envelope curve for concrete in compression that captures the effects of confinement [11]. The tensile strength of concrete is neglected, since it has minor effects on the flexural response of RC sections. Unloading and reloading paths follow the Karsan and Jirsa [12] model. Each unloading path starts from the envelope curve at a strain of $\varepsilon_{r}$ and follows a straight line connecting to point $\varepsilon_{p}$ (the strain when stress is zero). After the unloading path is completed, the concrete stress remains zero as the strain goes below $\varepsilon_{p}$. For the reloading path, concrete stress remains zero until the strain reaches $\varepsilon_{p}$. When strains exceed $\varepsilon_{p}$, the reloading path follows the previous unloading path. The loading and unloading is shown in Figure 3(a). Menegotto-Pinto [13] proposed a nonlinear hysteretic steel model which was extended by Filippou et al. [14] to include isotropic strain hardening effects. This stress-strain relationship is controlled by two straight-line asymptotes. One asymptote has a slope equal to $E_{0}$ (modulus of elasticity) while the other asymptote has a slope equal to $E_{1}=b E_{0}$ where $b$ is the strain hardening ratio. Figure 3(b) presents the hysteretic steel stress-strain relation.

\section{Determining Flexural and Shear Drifts of RC Shear Walls}

The total drift ratio of cantilever RC shear walls is the sum of the flexural drift component $R_{f}$ and the shear drift component $R_{S}$ as shown in Eq. 1.

$R_{t}=R_{f}+R_{s}$

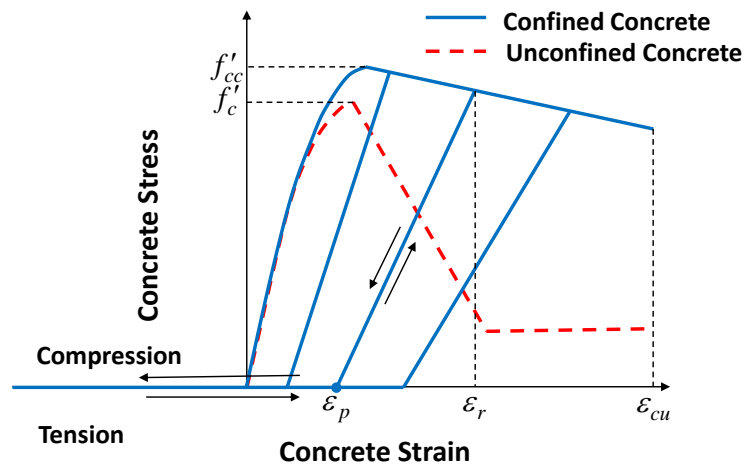

(a)

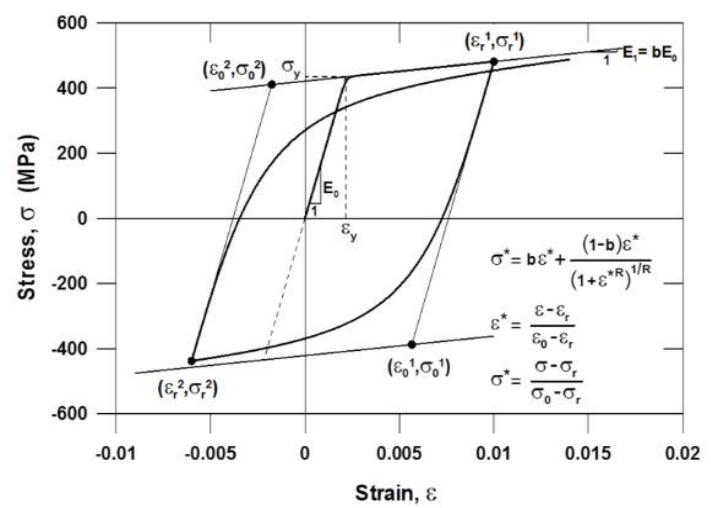

(b)

Figure 3: Stress-strain relations for concrete and steel bar under cyclic loading: (a) Hysteretic concrete stress-strain relation; and (b) Menegotto-Pinto steel model [15].

\section{Flexural Drift Component}

The flexure drift is assumed to be a combination of elastic deformation and plastic deformation as shown in Eq. 2. Figure 4 (c) presents the decomposition of flexural drift components.

$R_{f}=R_{f e}+R_{f p}=\frac{1}{H}\left(\Delta_{f e}+\Delta_{f p}\right)$

Where $R_{f e}$ is elastic drift and $R_{f p}$ is plastic drift, $H$ is shear span, and $\Delta_{f e}$ and $\Delta_{f p}$ are the elastic and plastic displacements, respectively. Where the RC shear walls act as a cantilever, the elastic displacement $\Delta_{f e}$ can be computed using basic elastic theory as shown in Eq. 3.

$\Delta_{f e}=\frac{Q H^{3}}{3 E I}$

The plastic curvature, $\phi_{f p}$, is evaluated by a fiber-based section analysis. Assuming the plastic curvature is constant over the plastic hinge length, $l_{p}$, the resulting plastic drift, $\Delta_{f p}$, is given by Eq. 4.

$\Delta_{f p}=l_{p} \phi_{f p}\left(H-0.5 l_{p}\right)$ 


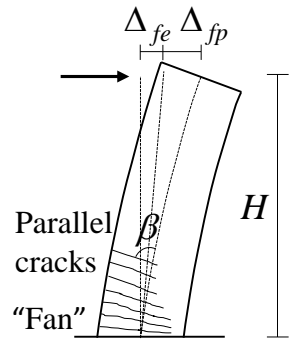

(a)

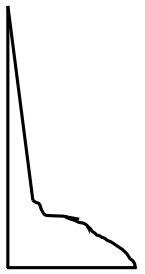

(b)

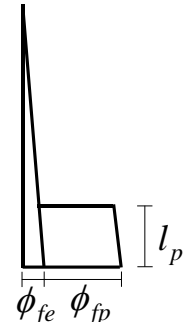

(c)
Figure 4: Decomposition of flexural drift components: (a) Flexural deformation; (b) Actual curvature distribution; (c) Idealized curvature distribution.

\section{Shear Drift Component}

Beyer et al. [16] proposed an equation to estimate the ratio of shear to flexural deformations for walls controlled by flexure. This model takes into account the effect of the mean axial strain on the shear deformation. The assumption of this model is that the ratio of shear-to-flexural deformations in a wall whose shear-transfer mechanism is not significantly degrading depends on the geometry of the wall, the axial stain level within the wall, and the cracking angle. The ratio of shear-to-flexural drifts is given in Eq. 5 .

$\frac{R_{S}}{R_{f}}=1.5 \frac{\varepsilon_{\text {mean }}}{\phi \tan \beta} \frac{1}{H}$

where $\varepsilon_{\text {mean }}$ and $\phi$ are the axial strain at the centre of the wall section and the curvature, respectively, and are derived from moment-curvature analysis. These two variables can be evaluated by a fibre-based section analysis. The cracking angle $\beta$ is the cracking angle outside the crack "fan" region where cracks are approximately parallel as shown in Figure 4 (a). Beyer et al. [16] suggest that this angle can be assumed to be 45 degrees for simplification. Alternatively, $\beta$ can be obtained by Eq. 6.

$$
\beta=\tan ^{-1}\left(\frac{j d}{V}\left(f_{l} t_{w}+\frac{A_{s w} f_{y w}}{s_{w}}\right)\right) \leq 90^{\circ}
$$

where $j d$ is the lever arm between the compression and tensile resultant, $V$ is shear force, $f_{l}$ is the tensile strength orthogonal to the crack, $t_{w}$ is wall thickness, and $A_{s w}, f_{y w}$ and $s_{w}$ are the area, yield strength and spacing of shear reinforcement in the web of the wall, respectively.

\section{Ultimate Point for Fibre-based Analysis}

The ultimate point occurs when one of the following three criteria is met: 1) load carrying capacity decreases to $80 \%$ of peak load, 2) the extreme compressive fibre of the confined concrete reaches the ultimate limit strain $\varepsilon_{c u}$ or 3) the strain of the longitudinal reinforcement reaches the ultimate limit which is $10 \%$ elongation. Criterion 1 is more appropriate to define the ultimate point for experimental work rather than numerical analyses. In this paper, all RC walls failed by crushing of concrete and fracture of longitudinal reinforcement failure mode (criterion 2) before the other two criteria. In criteria 2, the ultimate concrete strain is taken as the strain in the concrete when the transverse steel first fractures [10]. Mander et al. [17] proposed estimating the ultimate limit strain of confined concrete with Eq. 7.

$$
\varepsilon_{c u}=0.004+\frac{1.4 \rho_{s} f_{y h} \varepsilon_{m}}{f_{c c}^{\prime}}
$$

where $\rho_{s}$ is volumetric transverse reinforcement ratio, $f_{y h}$ is yield strength of the transverse reinforcement, $\varepsilon_{m}$ is the steel strain at the maximum tensile stress, and $f_{c c}{ }^{\prime}$ is confined compressive strength of the concrete.

\section{VALIDATION OF MODEL}

Before conducting a parametric study, the proposed model is validated with experimental data in order to have good accuracy. The equivalent plastic hinge length is required to determine the plastic drift. The equivalent plastic hinge length has been studied and several equations have been proposed. Although some researchers studied plastic hinge length in experiments to physically determine the plastic hinge in beams, columns, and walls, the procedure is still controversial. This paper employed the work based on parametric studies by Kono et al. [18] who compared eight equations for the equivalent plastic hinge length as shown in Table 1 and eight $\varepsilon_{m}$ 's (1\%-8\%). Based on their fourteen specimens, three combinations of $l_{p}$ and $\varepsilon m$ that give the best estimate of ultimate drift were found.

1. $l_{p}=0.2 l_{w}$ and $\varepsilon_{m}=6 \%$

2. $l_{p}=0.33 l_{w}$ and $\varepsilon_{m}=2 \%$

3. $l_{p}=0.5 l_{w}$ and $\varepsilon_{m}=1 \%$

No.1 in Table $1\left(l_{p}=\alpha l_{w}\right)$ is a simple way to describe $l_{p}$ with reasonable accuracy. ACI 318-99 provision [19] similarly suggests the plastic hinge length of $0.5 l_{w}$ to predict the design displacement. In this paper, the ultimate drift of forty-three tested specimens were compared to the ultimate drifts calculated by the proposed model using these three sets of $l_{p}$ and $\varepsilon_{m}$ in order to decide which combination of plastic hinge length and steel strain at the maximum tensile stress give the best estimation of ultimate drift. The test specimens used in this verification process cover experiments over the last 15 years and were selected by considering flexural failure, symmetry, good end region confinement, no shear sliding effect and $\rho_{s} d_{b} / d_{t}$ under 4 . The index $\rho_{s} d_{b} / d_{t}$ measures effectiveness of transverse reinforcement to prevent buckling and is called the buckling index [20]. It is suggested that keeping the buckling index below 1.2 will prevent buckling. In this study, shear walls with very high buckling indexes are considered to be prone to errors in estimating ultimate drift and are excluded from the calibration process. All tested walls used for validation were cantilevers. Table 2 shows the properties of the selected shear wall specimens and Table 3 shows the ratio of experimental to the computed ultimate drifts $\left(e^{R}{ }_{u} c^{R} R_{u}\right)$ along with the mean and standard deviation of this ratio. The forty-three tested walls used for validation were designed according to the standards listed below.

- AIJ standard: Ando corp. [30], Takenaka corp. [31], Okumura corp. [32] [33], Murakami et al. [36], Kabeyasawa et al. [39] and Kono et al. [9].

- Chinese code: Deng et al. [34] and Zhang et al. [37]

- Euro code: Dazio et al. [35]

- ACI318: Oh et al. [30] and Tran and Wallace [38]

The key parameters of the tested walls (Table 2) range as listed below.

- Concrete strength $=29.1-109.1 \mathrm{MPa}$

- Transverse reinforcement ratio $=0.56-3.00 \%$

- Axial load ratio $=0.02-0.30$

- Boundary column width $=100-250 \mathrm{~mm}$

- Boundary column depth $=150-540 \mathrm{~mm}$ 
Table 1: Existing equations to compute plastic hinge length.

\begin{tabular}{|c|l|l|}
\hline No. & \multicolumn{1}{|c|}{ Reference } & \multicolumn{1}{c|}{ Equation } \\
\hline 1 & $\begin{array}{l}\text { Thomsen and Wallace [21] } \\
\text { Kowalshi [22] } \\
\text { Kono et al. [20] }\end{array}$ & $l_{p}=\alpha l_{w}(\alpha$ was taken as 0.2, 0.33 and 0.5) \\
\hline 2 & $\begin{array}{l}\text { Wallace and Moehle [23] } \\
\text { Kabeyasawa et al. [24] } \\
\text { Takahashi et al. [25] }\end{array}$ & $l_{p}=\beta t_{w}(\beta$ was taken as 4) \\
\hline 3 & Paulay and Priestley [10] & $l_{p}=0.2 l_{w}+0.044 H$ \\
\hline 4 & Priestley at al. [26] & $l_{p}=0.08 H+0.15 f_{y} d_{b} l_{w}$ \\
\hline 5 & Panagioraks and Fardis [27] & $l_{p}=0.12 H+0.014 f_{y} d_{b} l_{w}$ \\
\hline 6 & Bohl and Adebar [28] & $l_{p}=\left(0.2 l_{w}+0.05 H\right)\left(1-1.15 N /\left(f_{c}^{\prime} A_{c}\right)\right)<0.8 l_{w}$ \\
\hline
\end{tabular}

$H$ is shear span. $l_{w}$ is length of wall. $d_{b}$ and $f_{y}$ are diameter and yield strength of longitudinal reinforcement, respectively. $N$ is axial load. $f_{c}^{\prime}$ is concrete compressive strength. $A_{c}$ is wall concrete cross section area

Table 2: Properties of shear wall specimens.

\begin{tabular}{|c|c|c|c|c|c|c|c|c|c|c|c|c|c|c|}
\hline \multirow{2}{*}{ No. } & \multirow{2}{*}{ Specim en } & \multirow{2}{*}{ R eference } & \multirow{2}{*}{$\begin{array}{c}\text { Size }(\mathrm{mm}) \\
I_{w} x h\end{array}$} & \multicolumn{5}{|c|}{ Confined area } & \multicolumn{3}{|c|}{ W allpaneI } & \multirow{2}{*}{$f_{c}(\mathrm{MPa})$} & \multirow{2}{*}{ AxailLevel } & \multirow{2}{*}{$\begin{array}{c}\text { Shear span } \\
\text { ratio }\end{array}$} \\
\hline & & & & $\operatorname{size}(\mathrm{m} m)$ & Ver. rebar & $f_{y}(\mathrm{M} \mathrm{pa})$ & Shear rebar & $\rho_{s}(\%)$ & Ver. rebar & Hor. rebar & $t_{w}(\mathrm{~mm})$ & & & \\
\hline 1 & W R-20 & \multirow{3}{*}{$\begin{array}{c}0 \text { h etal. } 2002 \\
{[19]}\end{array}$} & \multirow{3}{*}{$1500 \times 2000$} & \multirow{2}{*}{$200 \times 200$} & \multirow{2}{*}{$4-D 13$} & \multirow{3}{*}{449} & D 10@ 200 & 0.99 & \multirow{2}{*}{ 2-D 10@220 } & D 10@250 & \multirow{2}{*}{200} & 34.2 & \multirow{3}{*}{0.1} & \multirow{3}{*}{2.00} \\
\hline 2 & WR -10 & & & & & & D10@100 & 1.97 & & D10@ 200 & & 36.2 & & \\
\hline 3 & W B & & & $240 \times 240$ & $8-D 13$ & & D 10@ 150 & 0.94 & 2-D10@320 & D10@ 400 & 150 & 33.7 & & \\
\hline 4 & $\mathrm{~N} 0.1$ & \multirow{3}{*}{$\begin{array}{l}\text { Ando C orp. } \\
2003 \text { [20] }\end{array}$} & & & & & & & & & & 71.8 & 0.1 & \\
\hline 5 & $\mathrm{~N} 0.2$ & & $1500 \times 2250$ & $300 \times 150$ & $16-D 10$ & 569 & D 4@ 45 & 1.14 & 2-D6@60 & D 6@ 65 & 150 & 65.8 & 0.15 & 1.77 \\
\hline 6 & $\mathrm{~N} 0.3$ & & & & & & & & & & & 72.8 & 0.2 & \\
\hline 7 & $07 \mathrm{~N} 10$ & Takenaka & & & & & & & & & & & 0.1 & \\
\hline 8 & $07 N 15$ & C orp. 2006 & $1500 \times 2250$ & $300 \times 150$ & $14-D 13$ & 704 & D 6@ 65 & 1.9 & 2-D 10@100 & D 10@ 100 & 150 & 14.9 & 0.15 & 2.00 \\
\hline 9 & $10 \mathrm{~N} 10$ & & & & & & & & & & & 109.1 & 0.1 & \\
\hline 10 & $\mathrm{~N} 0.1$ & & & $268 \times 134$ & $16-D 10$ & 433 & D 4@ 40 & 1.56 & 2-D6@57 & & & 63.8 & & \\
\hline 11 & $\mathrm{~N} 0.2$ & Corp 2007 & $1070 \times 1940$ & $402 \times 134$ & $22-D 10$ & & & 1.52 & 2-D6@56 & $D 6 @ 60$ & 134 & & 02 & 200 \\
\hline 12 & $\mathrm{~N} 0.3$ & [2] & $1070 \times 1040$ & $268 \times 134$ & $17-D 10$ & 397 & D 4@35 & 2.65 & $2-16057$ & 00 & 104 & 660 & 0.2 & 2.00 \\
\hline 13 & N 0.4 & & & $200 \times 104$ & ש & (39) & D 4@ 40 & 1.97 & 1 & & & 00.9 & & \\
\hline 14 & $\mathrm{~N} 0.5$ & 0 kum ura & $1070 \times 1865$ & $201 \times 134$ & $15-D, 10$ & 435 & $D 4 @ 40$ & 181 & 2D क (1) 59 & $D$ 6@ 60 & 134 & 65.5 & 02 & 2.00 \\
\hline 15 & $\mathrm{~N} 0.6$ & C orp. 2008 & \begin{tabular}{|l|}
$1070 \times 2935$ \\
\end{tabular} & $201 \times 107$ & (10 & 700 & 人 & r.0 & 20 00 & 年 & (107 & 67.9 & $0.2^{2}$ & 3.00 \\
\hline 16 & HPCW -01 & & & $240 \times 100$ & $4-D 12+2-D 6.5$ & & $D 4 @ 60$ & 1.02 & & $D 650100$ & & & & \\
\hline 17 & HPCW -02 & D eng etal. & $1000 \times 2000$ & $340 \times 100$ & $4-D 12+4-D 6.5$ & D 12 $=433.3$ & $D 6 @ 60$ & 1.7 & $2-100$ & 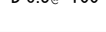 & 100 & 613 & 014 & 210 \\
\hline 18 & HPCW -03 & 2008 [24] & $1000 \times 2000$ & $340 \times 100$ & $6-D 12+2-D 6.5$ & D $6.5=361.6$ & $D 5, D 4 @ 40$ & 2.24 & 204000 & D 80 100 & 100 & 01.3 & 0.14 & 2.10 \\
\hline 19 & HPCW -04 & & & $440 \times 100$ & $5-D 12+6-D 6.5$ & & D 6,D 5,D 4@40 & 2.1 & & 年 & & & & \\
\hline 20 & W SH 1 & & & $200 \times 150$ & $6-D, 10$ & 547.3 & & 1.22 & $2-160125$ & & & 45 & 0.05 & \\
\hline 21 & W SH2 & & & & & 583.1 & D 6@ 75 & 1.25 & 2000 & & & 40.5 & 0.06 & 228 \\
\hline 22 & W SH3 & 2009 [25]. & $2000 \times 4030$ & $260 \times 150$ & $6-D 12$ & 601 & & 1.13 & 2-D8@125 & D 6@ 150 & 150 & 39.2 & 0.06 & 2.20 \\
\hline 23 & W SH 5 & & & $160 \times 150$ & $6-D 8$ & 583.7 & 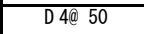 & 1.18 & $2-D 6 @ 140$ & & & 38.3 & 0.13 & \\
\hline 24 & W SH 6 & & & $385 \times 150$ & $6-D 12+2-D 8$ & 576 & $\bar{D} 6 @ 50$ & 1.82 & 2-D68@125 & & & 45.6 & 0.11 & 2.26 \\
\hline 25 & $\mathrm{H}$ & M urakam iet & $1120 \times 2140$ & $210 \times 134$ & $16-D 10$ & 409 & D4@ 40 & 1.42 & $2-D 6 @ 60$ & D 6@ 70 & 140 & 652 & 0.15 & 200 \\
\hline 26 & $\mathrm{H} 2$ & al. 2009 [26] & & & & & D 4@35 & 2.32 & & & & & 0.2 & \\
\hline 27 & SW 6-1 & & $1000 \times 2000$ & $200 \times 125$ & $6-D 10$ & & D 4@ 80 & 0.66 & & & & 37.5 & 0.3 & 2.20 \\
\hline 28 & SW 6-3 & Zhang etal. & & & & 352 & D6@60 & 2.25 & $2-060125$ & $D 60125$ & 125 & & & \\
\hline 29 & SW -2 & 2010 [27] & $850 \times 1600$ & $188 \times 125$ & $4-10$ & & $\begin{array}{l}\text { D 4@ } 83 \\
\end{array}$ & 0.56 & 2000 & De tav & 120 & 326 & 016 & 206 \\
\hline 30 & SW -3 & & $050 \times 1000$ & $10001<0$ & 4 व 10 & & D6@ 63 & 2.2 & & & & 02.0 & 0.10 & 2.00 \\
\hline 31 & $\begin{array}{c}\text { RW }-\mathrm{A} 20- \\
\mathrm{P} 10-\mathrm{S} 38\end{array}$ & & $1220 \times 2440$ & & $8-D 13$ & & & 1.85 & 2-D 6@ 140 & D 6@ 140 & & & 007 & 200 \\
\hline 32 & $\begin{array}{c}\text { RW -A20- } \\
\text { P10-S63 }\end{array}$ & & $12 \angle 0 \times<4+0$ & & 8-D 19 & & & 1.76 & 2-D 10@152 & D 10@ 52 & & 48 & 0.01 & 2.00 \\
\hline 33 & $\begin{array}{c}\text { RW -A15- } \\
\text { P10-S51 }\end{array}$ & W a llace 2012 & & $210 \times 150$ & $8-D 13$ & 475 & D 6@ 50 & 1.85 & 2-D 6@ 114 & D 6@ 114 & 150 & & 0.08 & \\
\hline 34 & RW -A15- & & $1220 \times 1830$ & & & & & & 2-D 10@127 & D 10@ 127 & & & 0.06 & 150 \\
\hline 04 & P10-S78 & & 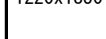 & & $4-D 19+4-D 16$ & & & 1.76 & 201000 & 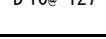 & & 56 & & \\
\hline 35 & $\begin{array}{l}\text { RW -A15- } \\
\text { P2.5-S64 }\end{array}$ & & & & & & & & 2-D 6@152 & D 10@ 152 & & & 0.02 & \\
\hline 36 & WA & & $1650 \times 1250$ & $150 \times 250$ & $10-D 10$ & 375 & & 0.57 & $2-04080$ & D 40 80 & 100 & 32.1 & 023 & 1.40 \\
\hline 37 & WB & Kabeyasaw a & & $250 \times 150$ & $10-010$ & $3 / 5$ & $D 4 @ 33$ & 0.68 & $2-14080$ & 04080 & 100 & 31.3 & 0.23 & 1.32 \\
\hline 38 & W C & etal.2014 [29] & $1750 \times 1250$ & $300 \times 150$ & $8 D 13$ & 345 & (5) & 0.57 & $2-D 4 @ 50$ & D 4@50 & 150 & 29.1 & 025 & 110 \\
\hline 39 & WD & & & $450 \times 100$ & 12D 10 & 365 & & 0.85 & 2-D4@75 & D 4@ 75 & 100 & 31.2 & $0 . \angle 0$ & 1.10 \\
\hline 40 & $\mathrm{NC40}$ & & & $540 \times 280$ & $12-D 10$ & & D6@ 40 & 3 & & & 128 & 525 & & \\
\hline 41 & $\mathrm{NC} 80$ & Kono etal. & $1750 \times 2800$ & & & 377 & D6@ 80 & 1.87 & $2-D 60200$ & D 60200 & & & 0.11 & 171 \\
\hline 42 & $B C 40$ & 2014 [9] & $1700 \times 2000$ & $250 \times 250$ & $8-D 10$ & (SII & D6@ 40 & 2.01 & 20000 & 0 & 80 & 595 & (1. & \\
\hline 43 & $\mathrm{BC} 80$ & & & 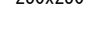 & (2) & & D6@ 80 & 0.72 & & & & & & \\
\hline
\end{tabular}

$l_{w} x h$ are external wall length and wall height, respectively. $\rho_{s}$ is shear rebar ratio in confined area. $t_{w}$ is wall thickness. 
Figure 5 shows the comparison between experimental and computed ultimate drifts. Specimens that did not meet all the criteria were excluded from the calibration process. Specimens $12-15,19,26,30,32,34,35$ and 40 were eliminated because their buckling index $\rho_{s} d_{b} / d_{t}$ exceeds 4 . Specimens 20,21, 23 and 41 were also eliminated due to shear sliding failure. Fifteen specimens were not included to compute the mean and standard division in Table 3 and in Figure 5. In the end, only twenty eight specimens were considered for the mean and standard deviation of $e^{R} u_{c} R_{u}$. It can be seen from Table 3 that the combination of $l_{p}=0.5 l_{w}$ and $\varepsilon_{m}=1 \%$ gives the mean closest to 1 and the lowest standard deviation of $e^{R}{ }_{u} / R_{u}$ among the three sets. The mean and standard deviation of $e^{R} u / c R_{u}$ were 1.28 and 0.53 , respectively. While the model has some error, it estimates the ultimate drift in relatively conservative way. Therefore, the parametric study uses half the wall length as the plastic hinge length and $1 \%$ as the transverse steel strain at the maximum stress.

\section{PARAMETRIC STUDY}

A parametric study was conducted to investigate the influence of important factors in design on the seismic behaviour of RC shear walls, particularly ultimate drift capacity. Five variables were studied: concrete strength, $f^{\prime}{ }_{c}$, volumetric transverse reinforcement ratio in the confined area, $\rho_{s}$, axial load ratio, $\eta$, boundary column width, B and boundary column depth, D. Rectangular cantilever structural walls (rectangular shape) and cantilever structural walls with columns at the end regions (barbell-shape) were analysed in various configurations. Figure 6 shows the strain and stress distribution of an RC shear wall with boundary columns. Drift is calculated from the curvature, $\phi$. It can be shown that the ultimate curvature is the ratio of the confined concrete limit strain at the ultimate state, $\varepsilon_{c u}$, to the neutral axis depth, $X_{n}$. Variation of either the limit strain or the neutral axis depth affects the ultimate curvature and thus the ultimate drift capacity. Specifically, an increase in the limit strain or a decrease in neutral axis depth will lead to an increase in ultimate curvature. The dimensions and reinforcement details for the prototype wall used in this parametric study are shown in Figure 7.

Table 3: Ratio of experimental and computed ultimate drifts.

\begin{tabular}{|c|c|c|c|c|c|c|c|c|c|}
\hline \multirow[b]{2}{*}{ No. } & \multirow[b]{2}{*}{ Specimen } & \multirow[b]{2}{*}{ Reference } & \multirow[b]{2}{*}{$\rho_{s} d_{b} / d_{t}$} & \multicolumn{2}{|c|}{$0.2 I_{w}+\varepsilon_{m}=6 \%$} & \multicolumn{2}{|c|}{$0.33 l_{w}+\varepsilon_{m}=2 \%$} & \multicolumn{2}{|c|}{$0.5 I_{w}+\varepsilon_{m}=1 \%$} \\
\hline & & & & $\begin{array}{l}{ }_{c} R_{u} \\
(\%)\end{array}$ & ${ }_{e} R_{u} / c R_{u}$ & $\begin{array}{l}{ }_{c} R_{u} \\
(\%)\end{array}$ & ${ }_{e} R_{u} /{ }_{c} R_{u}$ & $\begin{array}{l}{ }_{c} R_{u} \\
(\%)\end{array}$ & ${ }_{e} R_{u} / c R_{u}$ \\
\hline 1 & WR-20 & \multirow{3}{*}{ Oh et al. [29] } & 1.29 & 1.94 & 1.39 & 1.96 & 1.38 & 2.31 & 1.17 \\
\hline 2 & WR-10 & & 2.56 & 1.07 & 2.71 & 1.35 & 2.15 & 1.79 & 1.62 \\
\hline 3 & WB & & 1.22 & 1.58 & 1.78 & 1.91 & 1.46 & 2.29 & 1.22 \\
\hline 4 & No.1 & \multirow{3}{*}{$\begin{array}{c}\text { Ando Corp. } \\
\text { [30] }\end{array}$} & 2.86 & 1.37 & 1.09 & 1.40 & 1.07 & 1.67 & 0.90 \\
\hline 5 & No.2 & & 2.86 & 1.08 & 1.15 & 1.04 & 1.19 & 1.30 & 0.95 \\
\hline 6 & No.3 & & 2.86 & 0.82 & 1.18 & 0.91 & 1.07 & 1.06 & 0.92 \\
\hline 7 & 07N10 & \multirow{3}{*}{$\begin{array}{l}\text { Takenaka } \\
\text { Corp. [31] }\end{array}$} & 3.01 & 2.32 & 0.86 & 1.91 & 1.05 & 1.97 & 1.01 \\
\hline 8 & 07N15 & & 3.01 & 1.63 & 0.92 & 1.61 & 0.93 & 1.66 & 0.90 \\
\hline 9 & $10 \mathrm{~N} 10$ & & 3.01 & 2.03 & 0.99 & 1.76 & 1.14 & 1.91 & 1.05 \\
\hline 10 & No.1 & \multirow{4}{*}{$\begin{array}{l}\text { Okumura } \\
\text { Corp. [32] }\end{array}$} & 3.91 & 1.10 & 2.32 & 1.03 & 2.46 & 1.17 & 2.17 \\
\hline 11 & No.2 & & 3.81 & 1.00 & 2.72 & 0.95 & 2.84 & 1.08 & 2.50 \\
\hline 12 & No.3 & & $\underline{6.62}$ & 1.54 & 3.23 & 1.30 & 3.81 & 1.40 & 3.56 \\
\hline 13 & No.4 & & $\underline{4.94}$ & 1.27 & 3.54 & 1.14 & 3.93 & 1.27 & 3.53 \\
\hline 14 & No.5 & \multirow{2}{*}{$\begin{array}{l}\text { Okumura } \\
\text { Corp. [33] }\end{array}$} & 4.52 & 0.99 & 3.83 & 1.10 & 3.45 & 1.24 & 3.06 \\
\hline 15 & No. 6 & & 4.53 & 1.09 & 4.23 & 1.18 & 3.89 & 1.35 & 3.42 \\
\hline 16 & HPCW-01 & \multirow{4}{*}{$\begin{array}{l}\text { Deng et al. } \\
{[34]}\end{array}$} & 3.05 & 1.17 & 1.73 & 1.35 & 1.49 & 1.17 & 1.73 \\
\hline 17 & HPCW-02 & & 2.20 & 1.77 & 1.40 & 1.59 & 1.56 & 1.77 & 1.40 \\
\hline 18 & HPCW-03 & & 2.42 & 2.24 & 1.09 & 1.85 & 1.32 & 2.24 & 1.09 \\
\hline 19 & HPCW-04 & & 5.05 & 1.73 & 1.55 & 1.50 & 1.79 & 1.73 & 1.55 \\
\hline 20 & WSH1 & \multirow{5}{*}{$\begin{array}{l}\text { Dazio et al. } \\
\text { [35] }\end{array}$} & 2.04 & 3.25 & 0.32 & 3.23 & 0.32 & 3.25 & 0.32 \\
\hline 21 & WSH2 & & 2.09 & 2.63 & 0.53 & 2.78 & 0.50 & 2.63 & 0.53 \\
\hline 22 & WSH3 & & 2.25 & 1.99 & 1.02 & 2.08 & 0.98 & 1.99 & 1.02 \\
\hline 23 & WSH5 & & 2.36 & 1.29 & 1.05 & 1.59 & 0.86 & 1.29 & 1.05 \\
\hline 24 & WSH6 & & 3.64 & 1.67 & 1.24 & 1.86 & 1.11 & 1.67 & 1.24 \\
\hline 25 & $\mathrm{I}-1$ & \multirow{2}{*}{$\begin{array}{l}\text { Murakami et } \\
\text { al. [36] }\end{array}$} & 3.56 & 1.33 & 1.95 & 1.29 & 2.01 & 1.49 & 1.74 \\
\hline 26 & $\mathrm{I}-2$ & & $\underline{4.38}$ & 1.19 & 1.79 & 1.28 & 1.67 & 1.39 & 1.53 \\
\hline 27 & SW6-1 & \multirow{4}{*}{$\begin{array}{c}\text { Zhang et al. } \\
\text { [37] }\end{array}$} & 1.66 & 0.75 & 1.13 & 0.82 & 1.03 & 1.01 & 0.83 \\
\hline 28 & SW6-3 & & 3.76 & 1.76 & 0.61 & 1.46 & 0.73 & 1.53 & 0.70 \\
\hline 29 & SW-2 & & 1.66 & 0.46 & 4.85 & 0.60 & 3.72 & 0.73 & 3.04 \\
\hline 30 & SW-3 & & $\underline{4.25}$ & 0.75 & 3.01 & 0.88 & 2.57 & 1.01 & 2.25 \\
\hline 31 & RW-A20-P10-S38 & \multirow{5}{*}{$\begin{array}{c}\text { Tran and } \\
\text { Wallace [38] }\end{array}$} & 3.92 & 2.97 & 1.05 & 2.58 & 1.21 & 2.97 & 1.05 \\
\hline 32 & RW-A20-P10-S63 & & $\underline{5.63}$ & 2.50 & 1.20 & 2.13 & 1.40 & 2.50 & 1.20 \\
\hline 33 & RW-A15-P10-S51 & & $\overline{3.92}$ & 2.96 & 0.83 & 2.51 & 0.98 & 2.96 & 0.83 \\
\hline 34 & RW-A15-P10-S78 & & $\underline{4.66}$ & 2.19 & 1.03 & 2.09 & 1.08 & 2.19 & 1.03 \\
\hline 35 & RW-A15-P2.5-S64 & & $\overline{4.66}$ & 3.02 & 0.84 & 2.71 & 0.94 & 3.02 & 0.84 \\
\hline 36 & WA & \multirow{4}{*}{$\begin{array}{c}\text { Kabeyasawa } \\
\text { et al. [39] }\end{array}$} & 1.43 & 3.26 & 1.05 & 3.49 & 0.98 & 4.25 & 0.80 \\
\hline 37 & WB & & 1.70 & 2.19 & 1.23 & 2.22 & 1.22 & 2.66 & 1.02 \\
\hline 38 & WC & & 1.85 & 1.55 & 1.30 & 1.59 & 1.28 & 1.88 & 1.08 \\
\hline 39 & WD & & 2.13 & 1.21 & 1.26 & 1.22 & 1.25 & 1.42 & 1.08 \\
\hline 40 & NC40 & \multirow{4}{*}{$\begin{array}{c}\text { Kono et al. } \\
\text { [9] }\end{array}$} & $\underline{5.00}$ & 4.37 & 0.54 & 3.82 & 0.62 & 4.20 & 0.57 \\
\hline 41 & NC80 & & 3.11 & 2.17 & 0.69 & 2.47 & 0.61 & 3.13 & 0.48 \\
\hline 42 & BC40 & & 3.35 & 2.87 & 1.40 & 2.23 & 1.80 & 2.24 & 1.80 \\
\hline \multirow[t]{3}{*}{43} & $\mathrm{BC} 80$ & & 1.20 & 1.66 & 1.21 & 1.51 & 1.32 & 1.68 & 1.19 \\
\hline & & & & Mean & 1.47 & Mean & 1.43 & Mean & 1.28 \\
\hline & & & & SD & 0.82 & SD & 0.64 & $\mathrm{SD}$ & 0.53 \\
\hline
\end{tabular}

Underlined values of buckling index $\rho_{s} d_{b} / d_{t}$ exceed 4 . Eleven specimens have buckling index lager than 4. Specimen 20,21, 23 and 41 have shear sliding failure. These fifteen specimens were not included in the computation of mean and standard division in Table 3. 


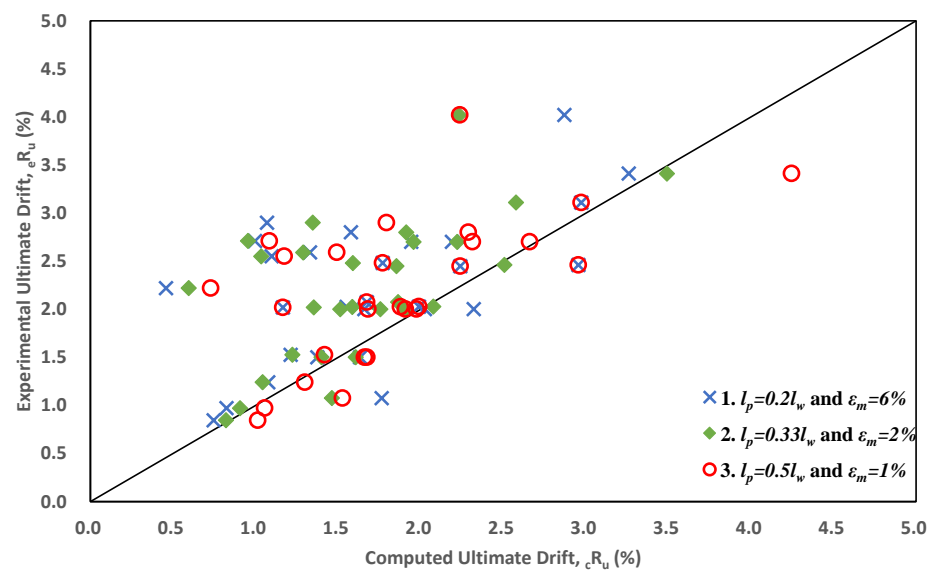

Figure 5: Comparison of experimental and computed ultimate drift.

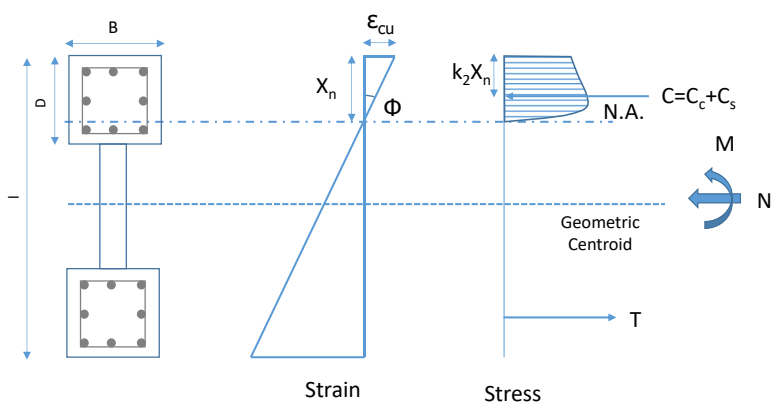

Figure 6: Strain and stress distribution of the ultimate flexural condition.

The prototypical wall in Figure 7 is used to explain the design of the parametric study. The equations of equilibrium for force and moment are given below.

$N=C-T$

$M=C\left(\frac{l}{2}-k_{z} X_{n}\right)+T\left(\frac{l}{2}-\frac{D}{2}\right)$

where $l$ is $1750 \mathrm{~mm}$ and $D$ is $250 \mathrm{~mm}$.

To isolate the effects of the parameters in this study, it was decided to keep the moment capacity as constant as possible. Two variables have the largest effect on $M: T$ and $D$. Note that once $T$ is fixed, $C, X_{n}$, and $k_{z}$ do not vary much for constant $N$. Thus, tension force, $T$, was held constant by keeping the same amount of longitudinal reinforcement $\left(568 \mathrm{~mm}^{2}\right.$ is equivalent to 8 -D10) and $D$ was held constant by having the steel centroid at the same location $(125 \mathrm{~mm}$ from the extreme tensile and compressive fibres) in every case. That is, a fixed amount of longitudinal reinforcement was lumped at $125 \mathrm{~mm}$ from the extreme fibres regardless of the boundary column dimensions. Variables affecting the ultimate drift were all set at the prototype case in Table 4 . When the influence of one factor was studied, this factor was varied while all other variables were fixed at the prototype case values. All RC shear walls had the same length $(1,750 \mathrm{~mm})$, height $(3000 \mathrm{~mm})$, and gross cross section areas $\left(2,250 \mathrm{~cm}^{2}\right)$. All specimens were designed to fail in flexure due to compressive failure of concrete with no buckling of the longitudinal reinforcement in the confined area. Vertical reinforcement in wall panels was omitted in order to minimize any changes in the tension force, $T$.

Table 4: Prototype case.

\begin{tabular}{|c|c|c|c|}
\hline$f_{C}^{\prime}(\mathrm{MPa})$ & 30 & Wall height $(\mathrm{mm})$ & 3000 \\
\hline$\rho_{S}(\%)$ & $\begin{array}{c}0.80 \\
(\mathrm{D} 6 @ 70.1)\end{array}$ & Wall length $(\mathrm{mm})$ & 1750 \\
\hline$\eta(\%)$ & 10 & Plastic hinge length $(\mathrm{mm})$ & 875 \\
\hline $\mathrm{B}(\mathrm{mm})$ & 250 & $\begin{array}{c}\text { Longitudinal rebar in } \\
\text { confined area }\end{array}$ & 8-D10 \\
\hline $\mathrm{D}(\mathrm{mm})$ & 250 & Gross section area $\left(\mathrm{mm}^{2}\right)$ & 225,000 \\
\hline
\end{tabular}

Table 5 lists the parametric study cases and resulting ultimate drifts. The prototype case had a concrete strength of $30 \mathrm{MPa}$, a shear reinforcement ratio of $0.80 \%$, an axial load ratio of $10 \%$ and a boundary column size of $250 \times 250 \mathrm{~mm}$. In the parametric study, concrete compressive strength was varied from $20 \mathrm{MPa}$ to $100 \mathrm{MPa}$. Concrete strength of $20 \mathrm{MPa}$ represents the lower limit of concrete strength currently used in construction while $100 \mathrm{MPa}$ represents high-strength concrete used in special situations. Young's modulus of concrete and Modulus of rupture were approximated by $E_{c}=4700 \sqrt{f_{c}^{\prime}}(\mathrm{MPa})$ and $f_{t}^{\prime}=0.62 \sqrt{f_{c}^{\prime}}$ (MPa) (ACI31814 [40]). The volumetric shear reinforcement ratio was varied from $0.20 \%$ to $1.40 \%$. The axial load ratio in the parametric study was varied from $0 \%$ to $50 \%$ of the gross concrete cross section capacity. The upper bound of axial load ratio was set at $50 \%$ to represent an extreme case under seismic event.

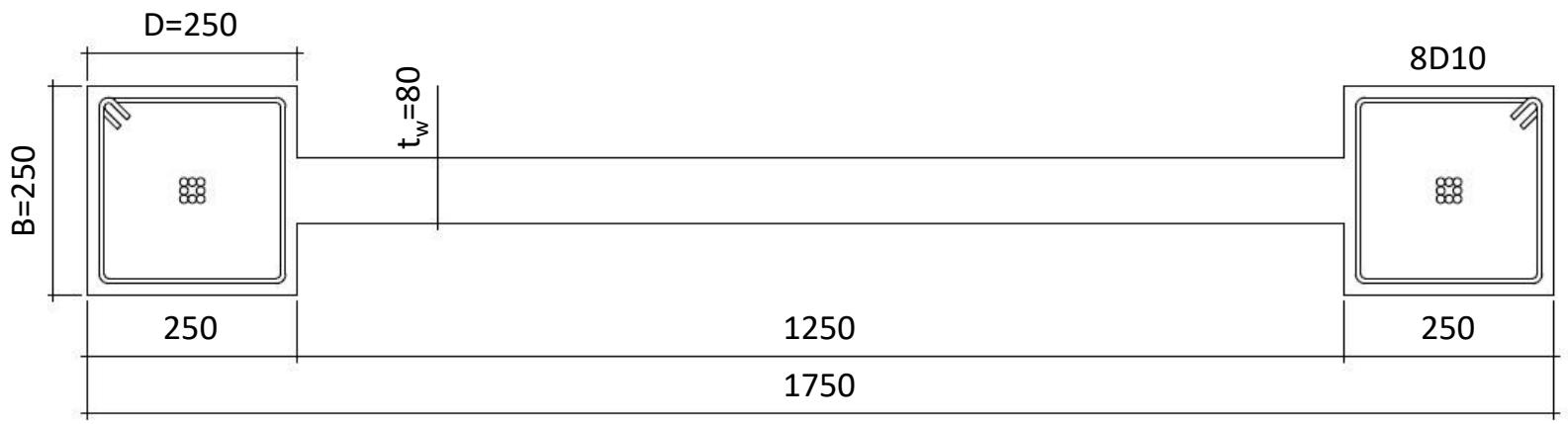

Figure 7: Dimension and reinforcement details of prototype specimen (mm). 
Table 5: Parametric studied cases and ultimate drift.

\begin{tabular}{|c|c|c|c|c|c|c|c|c|c|}
\hline \multirow[b]{2}{*}{ No. } & \multirow{2}{*}{$\begin{array}{l}\text { Studied } \\
\text { factor }\end{array}$} & \multirow{2}{*}{$\begin{array}{l}\text { Section } \\
\text { Type }\end{array}$} & \multirow{2}{*}{$\begin{array}{c}f_{c}^{\prime} \\
(\mathrm{MPa})\end{array}$} & \multirow[b]{2}{*}{$\rho_{s}(\%)$} & \multirow[b]{2}{*}{$\eta$} & \multicolumn{2}{|c|}{ Boundary column } & \multirow[b]{2}{*}{$t_{w}(\mathrm{~mm})$} & \multirow[b]{2}{*}{$\mathrm{R}_{\mathrm{u}}(\%)$} \\
\hline & & & & & & $B(\mathrm{~mm})$ & $\begin{array}{c}\mathrm{D} \\
(\mathrm{mm})\end{array}$ & & \\
\hline 1 & \multirow{9}{*}{$f_{c}^{\prime}$} & \multirow{9}{*}{ 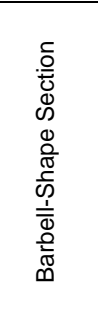 } & 20 & \multirow{9}{*}{0.80} & \multirow{9}{*}{0.10} & & & & 5.14 \\
\hline \#2 & & & 30 & & & & & & 4.67 \\
\hline 3 & & & 40 & & & & & & 4.51 \\
\hline 4 & & & 50 & & & & & & 4.39 \\
\hline 5 & & & 60 & & & 250 & 250 & 80.0 & 4.28 \\
\hline 6 & & & 70 & & & & & & 4.22 \\
\hline 7 & & & 80 & & & & & & 4.16 \\
\hline 8 & & & 90 & & & & & & 4.11 \\
\hline 9 & & & 100 & & & & & & 4.05 \\
\hline 10 & & 들 & & 0.20 & & & & & 3.54 \\
\hline 11 & & 窎 & & 0.40 & & & & & 4.02 \\
\hline 12 & & $\begin{array}{l}\infty \\
0\end{array}$ & & 0.60 & & & & & 4.44 \\
\hline$\# 13$ & $\rho_{s}$ & $\frac{\overline{0}}{\frac{0}{\pi}}$ & 30 & 0.80 & 0.10 & 250 & 250 & 80.0 & 4.67 \\
\hline 14 & & $\stackrel{\text { क्ल }}{=}$ & & 1.00 & & & & & 5.03 \\
\hline 15 & & $\overline{\bar{\Phi}}$ & & 1.20 & & & & & 5.39 \\
\hline 16 & & $\stackrel{\tilde{\tilde{D}}}{0}$ & & 1.40 & & & & & 5.68 \\
\hline 17 & & & & & 0.00 & & & & 8.80 \\
\hline 18 & & & & & 0.05 & & & & 6.55 \\
\hline$\# 19$ & & 든 & & & 0.10 & & & & 4.67 \\
\hline 20 & & $\overline{\bar{J}}$ & & & 0.15 & & & & 3.48 \\
\hline 21 & & क & & & 0.20 & & & & 2.51 \\
\hline 22 & $\eta$ & 을 & 30 & 0.80 & 0.25 & 250 & 250 & 80.0 & 1.93 \\
\hline 23 & & $\begin{array}{l}\text { क् } \\
\stackrel{=}{=}\end{array}$ & & & 0.30 & & & & 1.22 \\
\hline 24 & & 욘 & & & 0.35 & & & & 0.78 \\
\hline 25 & & Ф̄ & & & 0.40 & & & & 0.54 \\
\hline 26 & & & & & 0.45 & & & & 0.52 \\
\hline 27 & & & & & 0.50 & & & & 0.46 \\
\hline 28 & & & & & & & 100 & & 2.32 \\
\hline 29 & & 듬 & & & & & 150 & & 2.35 \\
\hline 30 & & ర్ల & & & & & 200 & & 2.40 \\
\hline 31 & & $\frac{\pi}{\omega}$ & 30 & & & & 250 & & 2.40 \\
\hline 32 & & $\frac{1}{5}$ & 30 & 0.80 & 0.10 & 128.6 & 300 & 128.6 & 2.45 \\
\hline 33 & & $\frac{\text { त् }}{0}$ & & & & & 350 & & 2.45 \\
\hline 34 & & $\begin{array}{l}\mathscr{D} \\
\propto \\
\propto 1\end{array}$ & & & & & 400 & & 2.45 \\
\hline 35 & & & & & & & 450 & & 2.40 \\
\hline 36 & & & & & & & 100 & 125.8 & 2.35 \\
\hline 37 & & & & & & & 150 & 124.1 & 2.75 \\
\hline 38 & & & & & & & 200 & 122.2 & 2.89 \\
\hline 39 & & & 30 & 0.80 & 0.10 & 150 & 250 & 120.0 & 2.94 \\
\hline 40 & & & & & & & 300 & 117.4 & 2.99 \\
\hline 41 & & & & & & & 350 & 114.3 & 2.94 \\
\hline 42 & ह్ & & & & & & 400 & 110.5 & 2.94 \\
\hline 43 & गे & & & & & & 100 & 119.4 & 3.04 \\
\hline 44 & $\geq$ & & & & & & 150 & 113.8 & 3.83 \\
\hline 45 & $\frac{\pi}{0}$ & 드 & 30 & 0 & 10 & 200 & 200 & 107.4 & 3.89 \\
\hline 46 & 亏ે & ت্ & 30 & 0.80 & 0.10 & 200 & 250 & 100.0 & 3.95 \\
\hline 47 & & $\begin{array}{l}\infty \\
0\end{array}$ & & & & & 300 & 91.3 & 4.00 \\
\hline 48 & & 뭉 & & & & & 350 & 81.0 & 4.00 \\
\hline 49 & & 京 & & & & & 100 & 112.9 & 3.95 \\
\hline 50 & & बू & & & & & 150 & 103.4 & 4.69 \\
\hline 51 & & 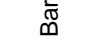 & 30 & 0.80 & 0.10 & 250 & 200 & 92.6 & 4.74 \\
\hline \#52 & & & & & & & 250 & 80.0 & 4.61 \\
\hline 53 & & & & & & & 300 & 65.2 & 4.73 \\
\hline 54 & & & & & & & 100 & 106.5 & 4.68 \\
\hline 55 & & & & & & & 150 & 93.1 & 5.29 \\
\hline 56 & & & 30 & 0.80 & 0.10 & 300 & 200 & 77.8 & 5.41 \\
\hline 57 & & & & & & & 250 & 60.0 & 5.40 \\
\hline 58 & & & & & & & 100 & 100.0 & 5.72 \\
\hline 59 & & & 30 & 0.80 & 0.10 & 350 & 150 & 82.8 & 5.89 \\
\hline 60 & & & & & & & 200 & 63.0 & 5.95 \\
\hline
\end{tabular}

\# Prototype case, $\rho_{s}$ volumetric shear reinforcement ratio, $\eta=N /\left(A_{c} x f^{\prime}\right), N$ axial load, $A_{c}$ Wall concrete cross section area, $B$ boundary column width, $D$ boundary column depth, $t_{w}$ thickness of wall panel, $R_{u}$ ultimate drift capacity 


\section{VARIATION OF ULTIMATE DRIFTS}

\section{Influence of Concrete Strength}

Cases 1 to 9 in Table 5 present the influence of concrete strength on the ultimate drift and are shown in Figure 8. The ultimate drift capacity degrades from $5.14 \%$ to $4.05 \%$ for walls with boundary columns when concrete strength increases from 20MPa to 100MPa. The degradation can be explained by equation 7 from Mander et al. [15], which is plotted in Figure 10 (a) for $f^{\prime}{ }^{\prime} .=30 \mathrm{MPa}$ and $40 \mathrm{MPa}$. Equation 7 is based on an energy balance approach. As shown in Figure 10, for equal energy (area under the stress-strain curve) when the concrete strength increases, the ultimate failure strain decreases. Thus, increasing the concrete strength reduces the failure strain, which, all else being equal, decreases the ultimate curvature. However, if $T$ and $N$ are constant in Equation 8, $C$ is constant and increasing the concrete strength will reduce the neutral axis, which, all else being equal, increases the ultimate curvature. Thus, increasing the concrete strength can decrease the ultimate curvature at failure due to a decrease in failure strain or increase the ultimate curvature at failure due to a decrease in neutral axis depth. In Figure 8, the drift at ultimate capacity is decreasing with increased concrete strength, so in this case the ultimate curvature reduction due to reduced failure strain is happening at a higher rate than the increase in ultimate curvature due to decreasing neutral axis. Also, for this case, the rate of change in ultimate drift capacity decreases with increased concrete strength. Whether these trends hold true for other combinations of axial load ratio, transverse steel ratio and boundary column dimensions needs further investigation.

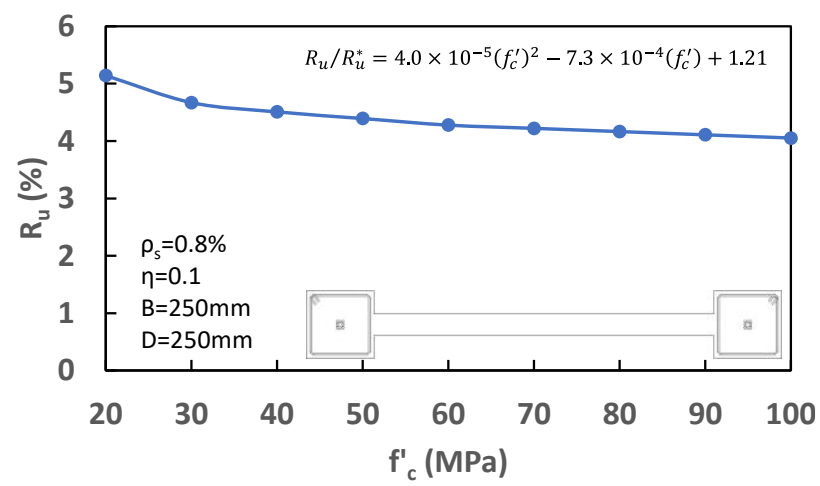

Figure 8: Influence of concrete strength on ultimate drift.

\section{Influence of Transverse Reinforcement Ratio}

Cases 10 to 16 in Table 5 present the influence of transverse reinforcement ratio on the ultimate drift and are shown in Figure 9. Additional transverse reinforcement in confined regions has benefit to drift angle at the ultimate point. Transverse reinforcement ratios were increased from $0.20 \%$ to $1.40 \%$ in walls with boundary columns resulting in increased ultimate drift capacity from $3.54 \%$ to $5.64 \%$. The effect of transverse reinforcement on the ultimate drift angle can be explained by Eq. 7 [15], which is plotted in Figure 10(b) for transverse shear reinforcement ratios of $0.8 \%$ and $1.0 \%$ for constant $f^{\prime}{ }_{c}$. Increased confinement leads to higher ultimate limit strain, $\varepsilon_{c u}$, and slightly higher concrete stresses. The increased ultimate strain increases ultimate curvature and the increased concrete strength reduces the neutral axis depth which also increases ultimate curvature. Therefore, the ultimate drift capacity definitely increases with increased transverse reinforcement.

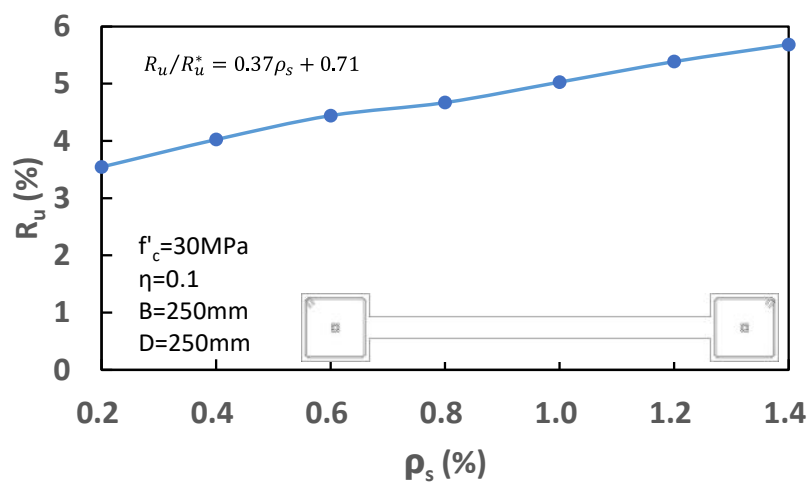

Figure 9: Influence of transverse reinforcement ratio on ultimate drift.

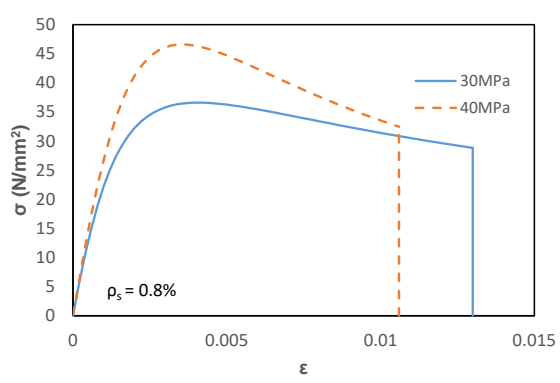

(a) Effect of concrete strength on stress-strain curve

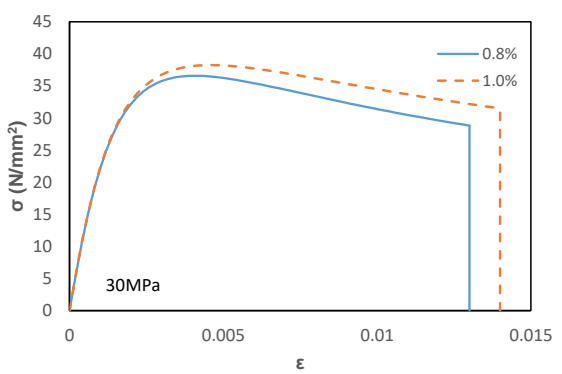

(b) Effect of confining reinforcement on stress-strain curve

Figure 10: Stress-strain relations for confined concrete.

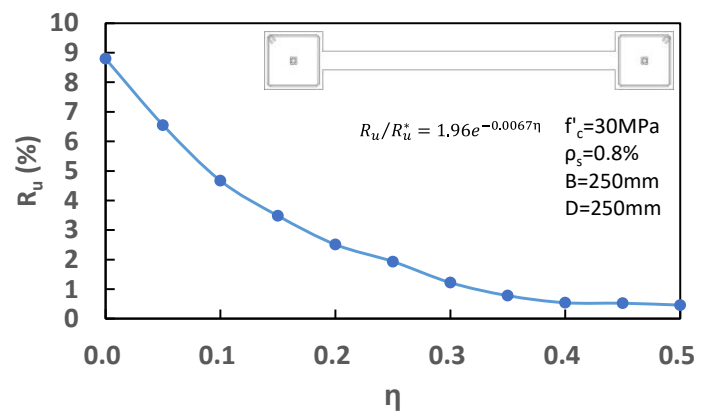

Figure 11: Influence of axial load ratio on ultimate drift.

\section{Influence of Axial Load Ratio}

Cases 17 to 27 in Table 5 present the influence of axial load ratio on the ultimate drift and are shown in Figure 11. The results show that increasing the axial load ratio from 0.0 to 0.5 reduces the ultimate drift capacity from $8.80 \%$ to $0.46 \%$ for walls with boundary columns. The drift capacity reduces dramatically as the axial load ratio increases from 0 to 0.2 and does not reduce much when the axial load ratio increases from 0.3 to 0.5 . When the axial load ratio is larger than 0.3 the entire cross section is in compression and the longitudinal 
reinforcement in the confined regions do not yield. Also, when the axial load ratio is larger than 0.3 , the extreme fibre of plain concrete (adjacent to the confined region) can reach its failure strain before the extreme fibre of the confined concrete reaches its failure strain.

\section{Influence of Boundary Column Dimensions}

Cases 28 to 60 in Table 5 present the influence of boundary column dimensions on the ultimate drift and are shown in Figures 12 and 13. Cases 28 to 35 are rectangular cross sections with $128.6 \mathrm{~mm}$ thick walls, while the remaining cases are barbell-shape sections. Because the gross cross section area is kept constant, as the boundary column dimensions change the wall thickness changes. Figure 12 clearly shows that as boundary column width increases the ultimate drift increases. This effect is the same for almost all boundary column depths, D. However, in some cases at the same boundary column width, B, some RC walls have an ultimate drift lower than others. This happens because for very small boundary column depths, $\mathrm{D}$, the neutral axis is outside of the boundary column width, B. Cases where this happen are presented as dashed circles in Figure 12. For boundary columns with depth, D, of $200 \mathrm{~mm}$, the ultimate drift increased from $2.40 \%$ to $5.95 \%$ as the boundary column width, B, increased from 128.6 to $350 \mathrm{~mm}$. For a given concrete compressive force, $\mathrm{C}$, and $f_{c}^{\prime}$, the area of concrete in compression is constant. Thus, a wider boundary column results in a smaller neutral axis depth, which increases ultimate curvature.

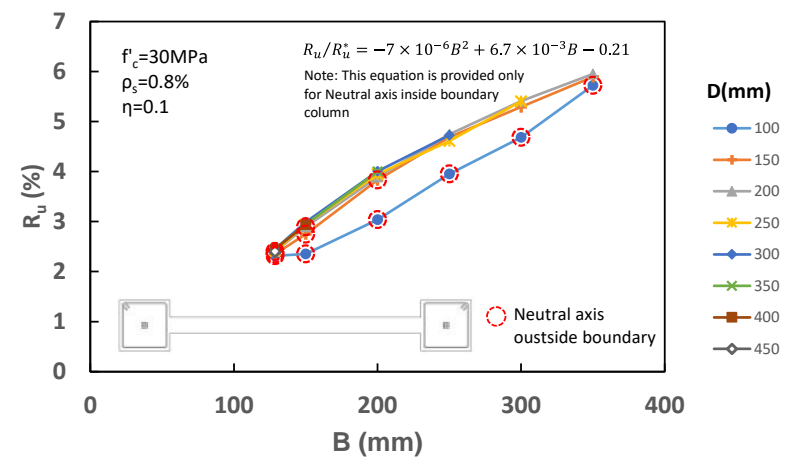

Figure 12: Influence of boundary column width on ultimate drift.

The effect of column depth, D, is shown in Figure 13. The ultimate drift increases considerably as boundary column depth, D, increases from $100-150 \mathrm{~mm}$, particularly for boundary column widths, B, of 200,250 , and $300 \mathrm{~mm}$. As D increases from $150 \mathrm{~mm}$ to $200 \mathrm{~mm}$ there is a small increase in ultimate drift. However, after $200 \mathrm{~mm}$ of column depth, the ultimate drift is constant; that is, it is independent of column depth. These trends can be explained by examining the neutral axis location as a function of column depth, D, shown in Figure 14. The diagonal unity line represents shear walls with neutral axes located at the intersection of the boundary column and wall panel. If the neutral axis is located inside the boundary column (below the diagonal), the neutral axis is independent of the column depth, D. This is because the compressive area $\left(B * X_{n}\right)$ is not affected as the boundary column depth increases into the tension zone. If the neutral axis is located outside the boundary column (above the diagonal) the neutral axis location varies with $\mathrm{D}$. To have the same compressive area, the neutral axis will need to shift within the wall as the boundary column area changes. This effect is complicated by the fact that the total gross cross section area of the wall is kept constant in this parametric study and that as the boundary column area changes, the wall thickness changes. A final observation about Figure 13 is that the ultimate drift for the rectangular wall $(B=128.6 \mathrm{~mm})$ is always less than the ultimate drift for all the barbell shape walls.

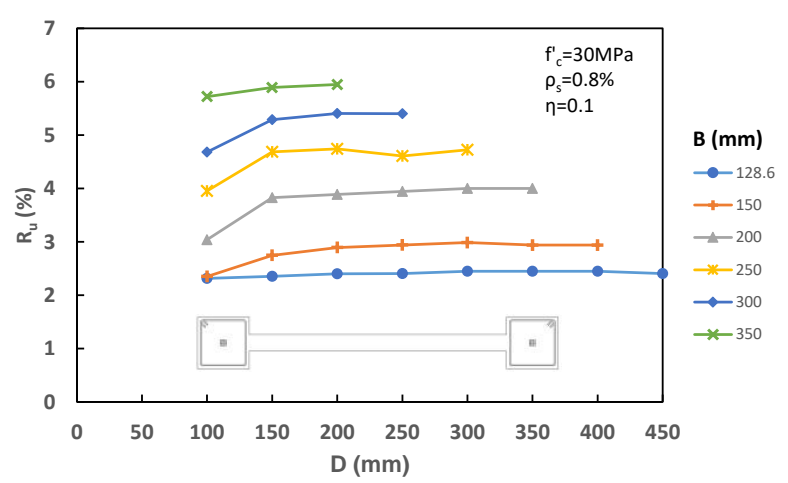

Figure 13: Influence of boundary column depth.

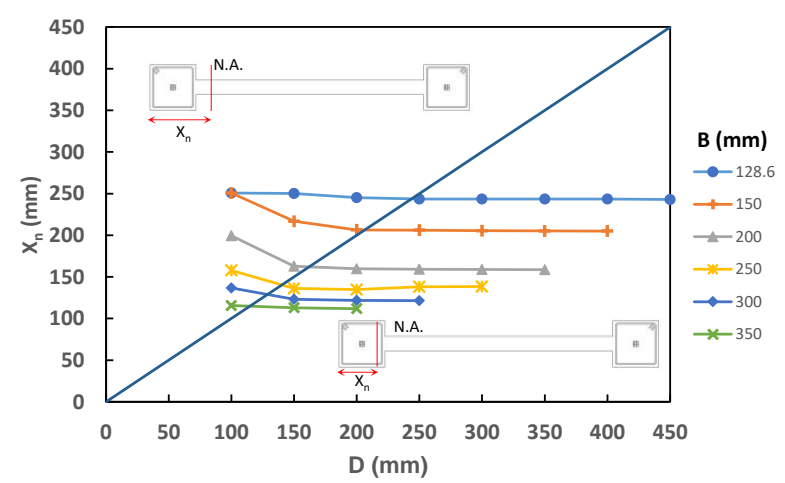

Figure 14: Influence of boundary column depth on ultimate drift on neutral axis location.

The equations in the Figure 8, 9, 11 and 12 show the effect of each variable on the ratio of the ultimate drifts of studied cases relative to the prototype case. $R_{u}^{*}$ is $4.67 \%$ which is the ultimate drift of the prototype case as presented in Table 4 . In future, more cases will be studied to propose a general equation to predict the ultimate drift.

\section{CONCLUSIONS}

The ultimate drift capacity of RC shear walls that fail in a crushing of concrete and fracture of longitudinal reinforcement failure mode was assessed by a calibrated fibrebased model. Although the model did not evaluate the experimental ultimate drift with very high accuracy, it is a conservative model for estimation. The effects of important design variables including concrete strength, volumetric ratio of transverse reinforcement in the confined area, axial load ratio and boundary column size on the ultimate drift was studied. The following conclusions are limited to changes of one variable at a time from the prototype case of concrete strength of $30 \mathrm{MPa}$, a shear reinforcement ratio of $0.80 \%$, an axial load ratio of $10 \%$ and a boundary column size of 250x250 mm.

- The axial load ratio is the most influential parameter among the four parameters. Increasing the axial load ratio from 0.0 to 0.5 results in the ultimate drift capacity deteriorating considerably, from $8.80 \%$ to $0.46 \%$. When the axial load ratio is larger than 0.3 , the extreme fibre of plain concrete (adjacent to the confined region) can reach its failure strain before the extreme fibre of the confined concrete reaches its failure strain. 
- Increased transverse reinforcement in the boundary region increases ultimate drift capacity. Increasing the transverse reinforcement from $0.2 \%$ to $1.4 \%$ improves the ultimate drift capacity from $3.54 \%$ to $5.64 \%$.

- Higher concrete strength slightly reduces the ultimate drift capacity. Increasing the concrete strength from $20 \mathrm{MPa}$ to $100 \mathrm{MPa}$ decreases drift at the ultimate point from $5.14 \%$ to $4.05 \%$.

- Larger boundary column width enhances the ultimate drift capacity for any column depth. When the column depth is $200 \mathrm{~mm}$, increasing the column width from $128.6 \mathrm{~mm}$ to $350 \mathrm{~mm}$ increases the ultimate drift from $2.40 \%$ to $5.95 \%$.

- For constant amounts of longitudinal steel reinforcement at fixed distances from the extreme fibres, if the neutral axis is located within the boundary column, the ultimate drift capacity is independent of boundary column depth. If the neutral axis is outside the boundary column, the ultimate drift capacity increases with larger column depth.

These conclusions lead to the following recommendations for $\mathrm{RC}$ shear wall design with conditions similar to the prototype case. First, particular attention must be paid to the axial load ratio. For example, for the prototype shear wall, an axial load ratio higher than 0.2 will result in an ultimate drift capacity of only $2.5 \%$. Second, the ultimate drift capacity of walls with boundary columns is always higher than that of rectangular walls with the same total gross area. Regarding sizing the boundary columns, a larger column width always improves the ultimate drifty capacity. The boundary column width should be set as wide as practical and limited to three times the wall width to ensure full cooperation between the boundary column and the wall based on the 1999 AIJ standard [2]. The boundary column depth needs to be longer than the largest anticipated neutral axis depth and at least half the column width to ensure that plane sections remain plane along the entire wall length including boundary regions. In this way, the boundary column size can be optimized for the required ultimate drift and practical construction constraints. Finally, the amount of transverse steel can also be adjusted to achieve desired drift capacities. The current analytical procedure gives very large ultimate drift capacity for some combinations of variables, but other failure modes such as shear sliding and overall buckling may precede the flexural failure in reality. In future, the other failure modes should be included in the computation procedure. In addition, ductile walls with the maximum ultimate drift larger than $4 \%$ may need experimental verification as well.

\section{ACKNOWLEDGEMENTS}

This study was conducted as Scientific Research A (PI: Susumu Kono) of 2015 JSPS Grant-in-Aid program. Some financial support was also granted by the Collaborative Research Project of Materials and Structures Laboratory of Tokyo Institute of Technology. The author has been supported by a MEXT scholarship.

\section{REFERENCES}

1 AIJ (2010). "Standard for Structural Calculation of Reinforced Concrete Structures". Architectural Institute of Japan, Tokyo.

2 AIJ (1999). "Standard for Structural Calculation of Reinforced Concrete Structures". Architectural Institute of Japan, Tokyo.

3 Kato H, Tajiri S and Mukai T (2010). "Preliminary Reconnaissance Report of the Chile Earthquake 2010". Building Research Institute (BRI), http://www.kenken.go.jp/english/pdf/progress-report-ofchile-eathquake.pdf. (Accessed 01/05/2017)

4 Telleen K, Maffei J, Heintz J and Dragovich J (2012).
"Practical lessons for concrete wall design, based on studies of the 2010 Chile earthquake". Proceedings of the $15^{\text {th }}$ World Conference on Earthquake Engineering, 24-28 September, Lisbon, Portugal.

5 Nishiyama M, Tani M, Idosako Y, Raouffard MM, Bedrinanna LA and Matsuba Y (2016). "A Preliminary Report about Structural Damages to RC/PC Buildings in Kumamoto Earthquake". Kyoto University, Kyoto, Japan.

6 Zhang Y and Wang Z (2000). "Seismic behavior of reinforced concrete shear walls subjected to high axial loading". ACI Structural Journal, 97(5): 739-750.

7 Su RKL and Wong SM (2007). "Seismic behavior of slender reinforced concrete shear walls under high axial load Ratio". Engineering Structures, 29(8): 1957-1965.

8 AIR Worldwide (2010). Chile Earthquake. http://alert.airworldwide.com/EventSummary.aspx? $=502 \& \mathrm{tp}=65 \& \mathrm{c}=1$. (Accessed 27/03/2017).

9 Kono S, Tani M, Mukai T, Fukuyama H, Taleb R and Sakashita M (2014). "Seismic behavior of reinforced concrete walls for a performance based design." Proceedings of the $2^{\text {nd }}$ European Conference on Earthquake Engineering and Seismology (2ECEES), August, Istanbul, Turkey.

10 Paulay T and Priestley MJN (1992). "Seismic Design of Reinforced Concrete and Masonry Buildings". John Wiley $\&$ Sons, New York, USA.

11 Scott BD, Park R and Priestley MJN (1982). "Stress-strian behavior of concrete confined by overlapping hoops at low and high strain rates". ACI Journal, 79(1): 13-27.

12 Karan ID and Jirsa JO (1969). "Behavior of concrete under compressive loadings". ASCE Journal of Structural Engineering, 95(12): 2543-2563.

13 Menegotto M and Pinto E (1973). "Method of analysis for cyclically loaded reinforced concrete plane frames including changes in geometry and non-elastic behavior of elements under combined normal force and bending". Proceedings of IABSE Symposium on Resistance and Ultimate Deformability of Structures Acted on by WellDefined Repeated Loads, Lisbon, Portugal.

14 Filippou FC, Popov EG and Bertero VV (1983). "Effects of Bond Deterioration on Hysteretic Behavior of Reinforced Concrete Joints". EERC Report No. UCB/EERC-83/19, Earthquake Engineering Research Center, University of California, Berkeley, USA.

15 Kolozvari K, Orakcal K and Wallace JW (2015). "ShearFlexure Interaction Modeling of Reinforced Concrete Structural Walls and Columns under Reversed Cyclic Loading". PEER Report No. 2015/12, Pacific Earthquake Engineering Research Center, University of California, Berkeley, USA.

16 Beyer K, Dazio A and Priestley MJN (2011). "Shear deformations of slender reinforced concrete walls under seismic loading". ACI Structural Journal, 108(2): 167177.

17 Mander JB, Priestley MJN and Park R (1988). "Observed stress-strain behavior of confined concrete". ASCE Journal of Structural Engineering, 114(8): 1827-1849.

18 Kono S, Obara T, Taleb R, Watanabe H, Tani M and Sakashita M (2015). "Simulation of drift capacity for RC walls with different section configurations". Proceedings of the $10^{\text {th }}$ Pacific Conference on Earthquake Engineering (10PCEE), 6-8 November, Sydney, Australia, pp.181-188.

19 ACI Committee 318 (1999). "Building Code Requirements for Structural Concrete (ACI 318-99) and Commentary (318R-99)". American Concrete Institute, Farmington Hills, Michigan, USA. 
20 Taleb R, Tani M and Kono S (2016). "Performance of confined boundary regions of RC walls under cyclic reversal loadings". Journal of Advanced Concrete Technology, 14: 108-124.

21 Thomsen JHIV and Wallace JW (2004). "Displacementbased design of slender reinforced concrete structural walls-experimental verification". ASCE Journal of Structural Engineering, 130(4): 618-630.

22 Kowalski MJ (2001). "RC structural walls designed according to UBC and displacement-based methods". ASCE Structural Journal, 127(5): 506-516.

23 Wallace JW and Moehle JP (1992). "Ductility and Detailing Requirements of Bearing Wall Buildings". Journal of Structural Engineering, 118(6): 1625-1644.

24 Kabeyasawa T, Kim Y, Sato M, Hyunseong $\mathrm{H}$ and Hosokawa Y (2011). "Tests and analysis on flexural deformability of reinforced concrete columns with wing walls". Proceedings of the $9^{\text {th }}$ Pacific Conference on Earthquake Engineering, Auckland, New Zealand, Paper ID 102.

25 Takahashi S, Yoshida K, Ichinose T, Sanada Y, Matsumoto K, Fukuyama H and Suwada H (2013). "Flexural Drift Capacity of Reinforced Concrete Wall with Limited Confinement". ACI Structural Journal, 110(1): 95-104.

26 Priestley MJN, Seible F and Calvi GM (1996). "Seismic Design and Retrofit of Bridges". John Wiley and Sons Inc., New York, USA.

27 Panagiorakos TB and Fardis MN (2001). "Deformations of reinforced concrete members at yielding and ultimate". ACI Structural Journal, 98(2): 135-148.

28 Bohl A and Adebar P (2011). "Plastic hinge lengths in high-rise concrete shear walls". ACI Structural Journal, 108(2): 148-157.

29 Oh YH, Han SW and Lee LH (2002). "Effect of boundary element details on the seismic deformation capacity of structural walls". Earthquake Engineering and Structural Dynamics, 31:1583-1602.

30 Tabata T, Nishihara H and Suzuki H (2003). "Bending moment curvature of extended RC shear walls". Proceedings of the Japan Concrete Institute, 25(2): 625630.

31 Kimura $\mathrm{H}$ and Ishikawa $\mathrm{Y}$ (2006). "Structural characteristic of RC rectangular cross section shear walls". Proceedings of the Japan Concrete Institute, 28(2): 469474.
32 Hosoya H (2007). "Study on structural performance of RC rectangular section core walls". Proceedings of the Japan Concrete Institute, 29(3): 313-318.

33 Kishimoto T, Hosoya H and Oka Y (2008). "Study on structural performance of $\mathrm{RC}$ rectangular section core walls". Summaries of technical papers of annual meeting, Architectural Institute of Japan, 355-358.

34 Deng M, Liang X and Yang K (2008). "Experimental study on seismic behaviour of high performance concrete shear wall with new strategy of transverse confining stirrups". Proceeding of the $14^{\text {th }}$ World Conference on Earthquake Engineering (14WCEE), October, Beijing, China.

35 Dazio A, Beyer K and Bachmann H (2009). "Quasi-Static cyclic tests and plastic hinge analysis of RC structural walls”. Engineering Structures, 31:1556-1571.

36 Murakami H, Tomatsuri H, Morimoto T, Hiwatashi T, Nakaoka A and Hirashi H (2009). "Experimental study on structural performance of RC multi-story shear wall". Proceeding of Architectural Institute of Japan Annual Convention, August, Japan.

37 Zhang H, Lu X and Wu X (2010). "Experimental study and numerical simulation of the reinforced concrete walls with different stirrup in boundary element". Journal of Asian Architecture and Building Engineering, 9(2): 447454.

38 Tran TA and Wallace JW (2012). "Experimental study of nonlinear flexural and shear deformation of reinforced concrete structural walls". Proceeding of the $15^{\text {th }}$ World Conference on Earthquake Engineering (15WCEE), September, Lisbon, Portugal.

39 Kabeyasawa $\mathrm{T}$, Kato $\mathrm{S}$, Sato $\mathrm{M}$, Kabeyasawa T, Fukuyama H, Tani M, Kim Y and Hosokawa Y (2014). "Effects of bi-directional lateral loading on the strength and deformability of reinforced concrete walls with/without boundary columns". Proceedings of the $10^{\text {th }}$ U.S. National Conference on Earthquake Engineering (10NCEE), July, Anchorage, Alaska, USA.

40 ACI Committee 318 (2014). "Building Code Requirements for Structural Concrete (ACI 318M-14) and Commentary (318RM-14)". American Concrete Institute, Farmington Hills, Michigan, USA. 